\title{
NECESIDAD DE INTERVENIR MILITARMENTE EN SUDÁN-DARFUR PARA SALVAGUARDAR LOS DERECHOS HUMANOS DE SUS POBLADORES*
}

\author{
Pablo César Revilla MontoyA**
}

RESUMEN: Las Naciones Unidas deben asumir su responsabilidad de proteger los derechos humanos e intervenir militarmente en el conflicto interno de Sudán, porque el gobierno sudanés está violando masiva y sistemáticamente los derechos humanos de la población, ocasionando una grave crisis humanitaria y posible genocidio.

ABSTRACT: The United Nations should assume their responsibility of protect the human rights and intervening militarily in the internal conflict of Sudan, since there are violating massive and systematically the human rights, causing a serious humanitarian crisis and possible genocide.

RÉSUMÉ: Les Nations Unies doivent assumer leur responsabilité de protéger les droits de l'homme et d'intervenir militairement dans le conflit interne du Soudan, parce que le gouvernement soudanais est en violation massive et systématiquement des droits de l'homme de la population, causant une crise humanitaire grave et possible génocide.

* Artículo recibido el 3 de julio de 2008 y aceptado para su publicación el 25 de julio de 2008 .

** Abogado y master en relaciones internacionales y comercio; profesor de Derechos humanos en la Universidad de San Martín de Porres y Alas Peruanas de Lima. 
SUMARIO: I. Introducción. II. El conflicto en Darfur. III. Uso de la fuerza en el derecho internacional. IV. La intervención humanitaria, la responsabilidad de proteger y la seguridad humana. V. Las Naciones Unidas y el conflicto en Sudán-Darfur. VI. Conclusiones. VII. Bibliografía.

\section{INTRODUCCIÓN}

Sudán ${ }^{1}$ es un Estado dividido por guerras civiles. Darfur, ${ }^{2}$ de mayoría negra-musulmana, es una región ubicada al extremo noroeste del país, que sufre un conflicto armado contra el gobierno central, de mayoría árabe-musulmana. Este conflicto es un claro ejemplo de la inoperatividad del Consejo de Seguridad ante crisis humanitarias.

Nosotros planteamos que Naciones Unidas debe intervenir militarmente en Sudán, ya que en estos momentos se están violando masiva y sistemáticamente los derechos humanos de la población, ocasionando una grave crisis humanitaria y posible genocidio.

Para confirmar nuestra hipótesis expondremos los hechos más relevantes del conflicto en Darfur, el uso de la fuerza en el derecho internacional, la intervención humanitaria y doctrina de la "responsabilidad de proteger" y, finalmente, criticaremos la actuación de las Naciones Unidas.

\section{EL CONFLICTO EN DARFUR}

Para realizar un mejor análisis de la situación fáctica, dividimos este apartado en antecedentes, hechos y la descripción de la crisis humanitaria en Darfur. Al finalizar esta sección el lector podrá entender los motivos que dieron inicio al conflicto, así como los hechos que nos llevan a afirmar que la crisis humanitaria no sólo se ha agravado, sino que también se ha internacionalizado.

\section{Antecedentes}

En la antigüedad, Nubia, o Sudán, estuvo dominada por los faraones egipcios, sin embargo, el Imperio Romano y luego el Bizantino controla-

1 La República de Sudán es el Estado más grande de África, situado al noreste del continente.

2 Darfur tiene una extensión territorial similar a la de Francia. 
ron toda la región, cristianizándola. Más adelante, los musulmanes de la etnia funj dominaron la zona hasta 1821, cuando Egipto, en ese entonces provincia del Imperio Otomano, conquistó el territorio. Empero, el sultanato de Darfûr consiguió conservar su independencia hasta bien entrado el periodo de dominio británico.

Tras la caída del Mahdí ${ }^{3}$ — que había tomado Jartum a finales del siglo XIX, luego de una serie de revueltas contra la dominación turco egipcia - una coalición anglo-egipcia dominó la zona mediante un condominio que en la práctica era ejercido con mayor poder por los británicos. No obstante, luego de la Segunda Guerra Mundial las relaciones entre estos dos Estados se verían enturbiadas y Egipto pediría el retiro del Reino Unido de Sudán.

Cuando por fin Sudán obtiene su independencia el 1o. de enero de 1956, se evidenciaba una diferencia abismal entre el norte de Sudán, que gobernaba el Estado, y las zonas meridionales, en especial el sur, que fue administrado por los británicos y que su población era mayoritariamente negra animista o cristianizada.

La primera guerra civil sudanesa, llevada a cabo de 1956 a 1972 entre el norte (musulmán) y el sur (negro animista y cristiano), tenía motivaciones autonomistas; sin embargo, la segunda guerra civil, iniciada en 1983, se originó a causa de la imposición de la Sharia o ley islámica.

A pesar de la firma del Acuerdo General de Paz entre el gobierno de Sudán y el Movimiento y Ejército de Liberación del Pueblo Sudanés (SPLM/A), que tuvo lugar el 9 de enero de 2005 en Nairobi, Kenya, se siguen llevando a cabo actos de agresión en la zona.

El Consejo de Seguridad emitió una resolución ${ }^{4}$ creando la Misión de las Naciones Unidas en el Sudán (UNMIS), para prestar apoyo en la aplicación del Acuerdo General de Paz. La Misión cuenta con un contingente de hasta 10,000 efectivos militares y un componente civil de hasta 715 policías civiles.

Sin embargo, cuando el país todavía no se recuperaba de la guerra civil, se dio inicio a otro conflicto interno con características distintas, ya que comprende a pueblos musulmanes de las etnias fur, zaghawa y masalit (negros), y los de la étnica abbala (de origen árabe).

3 Muhammad Ahmed Ibn Abd-Allâh (1843-1885).

4 S/RES/1590 (2005), aprobada por el Consejo de Seguridad en su 5151a. sesión, celebrada el 24 de marzo de 2005. 


\section{Hechos}

Desde inicios de 2003 los grupos rebeldes 5 de Darfur comenzaron a atacar blancos estatales, acusando al gobierno de oprimir a la población negra. En represalia, milicias pro gobierno, conocidas como janjaweed ${ }^{6}$ respondieron lanzando ataques contra la población afro de Darfur.

A las milicias janjaweed se les acusa de ejecutar una campaña de limpieza étnica, buscando expulsar a la población negra de grandes extensiones de tierra en Darfur, donde el agua es el recurso más escaso.

Oficialmente, el gobierno del presidente sudanés Omar al-Bashir niega cualquier vínculo con las milicias janjaweed, sin embargo, las sospechas de que su gobierno tiene como estrategia promover a los grupos paramilitares para frenar a la insurgencia en Darfur son cada día mayores.

Así, refugiados provenientes de Darfur describen ataques aéreos lanzados desde aviones del gobierno, seguidos de hordas de milicianos montados en caballos y camellos, que llegan a las aldeas para matar hombres, violar mujeres y robar todo lo que encuentran a su paso. Asimismo, muchas mujeres dicen haber sido secuestradas por los janjaweed y mantenidas como esclavas sexuales. ${ }^{7}$

\section{La crisis humanitaria en Darfur y la internacionalización del conflicto}

Lamentablemente, la actual tragedia humanitaria que sufre la región de Darfur, en Sudán, aparece de manera intermitente en las noticias del mundo; sin embargo, la cantidad de víctimas que ocasiona este conflicto es de escala tal que empequeñece las amenazas que enfrentan los habitantes de los países desarrollados. ${ }^{8}$

El conflicto armado en Darfur empezó a principios de 2003 y desde esa fecha se estima que 200,000 civiles han sido asesinados y casi $2 \mathrm{mi}-$

5 Existen dos grupos rebeldes en Darfur: el Ejército de Liberación de Sudán y el Movimiento por la Justicia y la Igualdad. El primero firmó un acuerdo de paz con el gobierno, pero sus dirigentes no lo aceptan, dividiendo al grupo en facciones armadas.

6 Milicia árabe musulmana conformada por ganaderos baggara en la región de Darfur, significa "jinetes armados".

7 Véase BBC Mundo, Darfur: claves de una tragedia, 26 de mayo de 2005, http:// news.bbc.co.uk/hi/spanish/international/newsid_4225000/4225823.stm

8 Programa de las Naciones Unidas para el Desarrollo, Informe sobre Desarrollo Humano 2005, Nueva York, Ediciones Mundi-Prensa, 2005, p. 173. 
llones de personas han sido desplazadas; las posesiones de esta población han sido saqueadas y la economía ha sido totalmente destruida. Asimismo, un número sin revelar de hombres, mujeres y niños han sido víctimas de crímenes de guerra, crímenes contra la humanidad y limpieza étnica. ${ }^{9}$

A ello se suma el incumplimiento del Acuerdo de Cesación del Fuego de Ndjamena, capital de Chad, del 8 de abril de 2004, y de los Protocolos Humanitario y de Seguridad de Abuja, capital de Nigeria, del 9 de noviembre de 2004, concertados entre el gobierno de Sudán, el Movimiento y Ejército de Liberación de Sudán y el Movimiento Justicia e Igualdad.

Ante la presión de la comunidad internacional, el gobierno sudanés anunció el 6 de julio de 2004 el desarme de la milicia Janjaweed así como el levantamiento de las restricciones a la ayuda humanitaria y la autorización del despliegue de 300 soldados de la Unión Africana ${ }^{10}$ para proteger a los observadores del alto al fuego en las provincias de Dafur. No obstante, Sudán decretó el 27 de julio de 2004 la movilización general "política y estratégica" en todos los cuerpos de Estado, afirmando que pretendía así resistir a toda tentativa de intervención de fuerzas internacionales en Dafur. ${ }^{11}$

Por otro lado, se afirma que los 1.7 millones de desplazados de Darfur han sido despojados de sus casas y granjas, y amenazados de muerte por las milicias janjaweed si tratan de regresar. Adicionalmente, existen 208,000 refugiados en Chad. Tomando en cuenta que en Darfur miles de personas que aun cuando no han sido desplazadas, se han visto empobrecidas por el fracaso de la economía rural causada por la violencia continua en el campo. Un total de 3.5 millones de personas que viven en Darfur — más de la mitad de la población de la región — tienen la necesidad de ayuda humanitaria. ${ }^{12}$

9 Human Right Watch, Darfur: Humanitarian Aid under Siege, núm. 1, mayo de 2006, p. 6, http://hrw.org/backgrounder/africa/sudan0506/darfur0506.pdf

10 Organización internacional creada en marzo del 2001 en reemplazo de la Organización para la Unidad Africana. Inspirada en la Unión Europea, tiene poderes supranacionales.

11 Dirección General de Comunicación Exterior de España, "Sudán”, Ministerio de Asuntos Exteriores y de Cooperación de España, junio de 2004, p. 21, http://www. mae.es/NR/rdonlyres/03CC364B-AA94-4145-8303-90CB98BA3A9A/4347/Sudan1.pdf.

12 Idem. 
A pesar de la existencia de un contingente de 7,000 efectivos de las fuerzas de paz de la Unión Africana, y las resoluciones del Consejo de Seguridad de la Organización de las Naciones Unidas, que ordenan el despliegue de fuerzas de paz, los ataques a la población civil continúan.

Finalmente, podemos agregar que la crisis humanitaria en $\mathrm{Su}-$ dán-Darfur se ha internacionalizado por dos razones: las violaciones masivas y sistemáticas a los derechos humanos y al derecho internacional humanitario, y los constantes ataques transfronterizos que los yanyawid sudaneses lanzan desde Darfur hacia los campos de refugiados en el Chad. ${ }^{13}$ En ese sentido, hay que recordar que una de las formas de configurar el crimen del genocidio es el sometimiento intencional a condiciones de existencia que han de acarrear la destrucción física, total o parcial a un grupo nacional, étnico, racial o religioso. ${ }^{14}$

\section{USO DE LA FUERZA EN EL DERECHO INTERNACIONAL}

En este apartado expondremos la evolución del uso de la fuerza en el derecho internacional contemporáneo y con ello probaremos que existen algunas formas no contempladas en la Carta de las Naciones Unidas.

Luego de la Primera Guerra Mundial, surge el Pacto de la Sociedad de Naciones que sin embargo no prohíbe la guerra, pero en su artículo 12 trata de retrasarla:

Todos los miembros de la Liga convienen en que si surge entre ellos alguna diferencia susceptible de producir una ruptura, la someterán bien al procedimiento del arbitraje, ya al examen del Consejo. Convienen, además, en que en ningún caso deberán recurrir a la guerra antes de que expire un plazo de tres meses después de la sentencia de los árbitros o del informe del Consejo.

En todos los casos previstos por este artículo, la sentencia de los árbitros se dictará en un plazo razonable, y el Consejo deberá emitir su infor-

13 Véase AFR 20/006/2006, Chad/Sudán. El fruto de las semillas de Darfur. Ataques étnicos en Chad de las milicias yanyawid de Sudán, del 28 de junio de 2006, informe de Amnistía Internacional que entre otras cosas documenta homicidios a manos de los yanyawid y desplazamientos forzados de la población civil a causa de los ataques de estas milicias.

14 Cfr. Convenio sobre la Prevención y Castigo del Delito de Genocidio de 1948, artículo 2o., párrafo c. 
me en el plazo de seis meses a contar desde la fecha en que se le haya sometido la diferencia.

Más adelante los diversos Estados se comprometieron con el Pacto Briand-Kellogg de $1948^{15}$ o pacto general de renuncia a la guerra. Sin embargo, a pesar de haberlo ratificado, muchos Estados siguieron utilizando su fuerza armada sin declarar la guerra, lo que no habría estado prohibido en strictu sensu.

Con el nacimiento de las Naciones Unidas, terminada la Segunda Guerra Mundial, se proclama como regla de derecho internacional el principio de prohibición del uso de la fuerza.

La Carta de las Naciones Unidas, artículo 2o., párrafo 4, prescribe que:

Los miembros de la Organización, en sus relaciones internacionales, se abstendrán de recurrir a la amenaza o al uso de la fuerza contra la integridad territorial o la independencia política de cualquier Estado, o en cualquier otra forma incompatible con los Propósitos de las Naciones Unidas.

Esta abstención no sólo de la fuerza, sino de la amenaza de su uso, significa que los Estados no podrán hacer uso de su fuerza armada ${ }^{16}$ en sus relaciones con otros Estados, mas no prohíbe otras medidas no coercitivas como las sanciones económicas.

La Asamblea General de la ONU ha contribuido al desarrollo del principio de prohibición del uso de la fuerza, así, la declaración sobre los principios de derecho internacional referente a las relaciones de amistad y a la cooperación entre los Estados de conformidad con la Carta de las Naciones Unidas, ${ }^{17}$ indica que:

Todo Estado tiene el deber de abstenerse, en sus relaciones internacionales, de recurrir a la amenaza o al uso de la fuerza...

Una guerra de agresión constituye un crimen contra la paz...

Todo Estado tiene el deber de abstenerse de organizar o fomentar la organización de fuerzas irregulares o de bandas armadas, incluidos los mercenarios, para hacer incursión en el territorio de otro Estado.

15 Firmado en París el 27 de agosto de 1928.

16 En ese sentido, véase Jiménez de Aréchaga, Eduardo, Derecho constitucional de las Naciones Unidas, Madrid, 1958, citado por Diez de Velasco, Manuel, Instituciones de derecho internacional público, Madrid, Tecnos, 2001, p. 848.

17 Resolución AG 2625 (XXV), adoptada el 24 de octubre de 1970. 
Todo Estado tiene el deber de abstenerse de organizar, instigar, ayudar o participar en actos de guerra civil o en actos de terrorismo en otro Estado o de consentir actividades organizadas dentro de su territorio encaminadas a la comisión de dichos actos...

La Corte Internacional de Justicia (CIJ) se ha pronunciado sobre la cualidad consuetudinaria del principio que estamos estudiando.

En el caso sobre las Actividades militares y paramilitares en y en contra de Nicaragua, la CIJ, en su sentencia del 27 de junio de 1986, expresó que existe en el derecho internacional consuetudinario una opinio iuris respecto a la calidad obligatoria de tal principio, que puede ser deducida, inter alia, de la actitud de las partes y de los Estados hacia ciertas resoluciones de la Asamblea General, particularmente la resolución 2625 $(\mathrm{XXV}) .{ }^{18}$

El principio de no empleo de la fuerza, opina la Corte, ${ }^{19}$ puede ser considerado como un principio de derecho internacional consuetudinario, no condicionado por las previsiones que se relacionan con la seguridad colectiva, o las facilidades o contingentes armados a ser suministrados bajo el artículo 43 de la carta.

Sin embargo, en el caso citado, la CIJ opinó que, mientras suministrar armas y entrenar a los "contras" 20 puede indubitablemente involucrar la amenaza o el empleo de la fuerza contra Nicaragua, esto no necesariamente ocurre respecto a todas las formas de ayuda del gobierno de Estados Unidos. En particular, la Corte considera que el mero envío de fondos a los "contras", aunque constituye sin duda una intervención en los asuntos internos, no supone en sí mismo un uso de la fuerza. ${ }^{21}$

\section{Excepciones a la prohibición del uso de la fuerza}

Tiempo atrás se quiso interpretar el artículo 2o., párrafo 4, de la Carta de las Naciones Unidas, especialmente la frase "contra la integridad te-

18 Caso sobre las Actividades militares y paramilitares en y en contra de Nicaragua, sentencia del 27 de junio de 1986, párrafo 188, de la Corte Internacional de Justicia.

19 Idem.

20 Grupo armado de resistencia nicaragüense.

21 Cfr. caso sobre las Actividades militares y paramilitares en y en contra de Nicaragua, sentencia del 27 de junio de 1986, párrafo 228. 
rritorial o la independencia política de cualquier Estado" en un sentido estricto.

Ejemplo de ello fue el caso del Canal de Corfú, Reino Unido de Gran Bretaña vs. Albania (1949), en el que Gran Bretaña arguyó ante la Corte Internacional de Justicia que una operación de limpieza de minas efectuada por sus unidades navales en aguas territoriales albanesas no era contraria al artículo 2o., párrafo 4, de la carta, porque tal acción no amenazó ni la integridad territorial ni la independencia política de Albania.

En respuesta a ello, la CIJ en su sentencia sobre el caso del Canal de Corfú, sostuvo que:

Sólo puede considerar al pretendido derecho de intervención como la manifestación de una política de fuerza, que en el pasado ha ocasionado los más graves abusos y que, cualesquiera que sean las deficiencias del sistema actual de organización internacional, no encuentra lugar alguno en el derecho internacional. La intervención es quizá menos aceptable en la forma particular que presenta en este caso, puesto que reservada por la naturaleza de las cosas a los Estados más poderosos, podría llevar fácilmente a falsear la administración de la justicia internacional. ${ }^{22}$

\section{A. Legítima defensa individual y colectiva}

La legítima defensa la encontramos regulada en la Carta de las Naciones Unidas, artículo 51, de la siguiente manera:

Ninguna disposición de esta Carta menoscabará el derecho inmanente de legítima defensa, individual o colectiva, en caso de ataque armado contra un Miembro de las Naciones Unidas, hasta tanto que el Consejo de Seguridad haya tomado las medidas necesarias para mantener la paz y la seguridad internacionales. Las medidas tomadas por los Miembros en ejercicio del derecho de legítima defensa serán comunicadas inmediatamente al Consejo de Seguridad, y no afectarán en manera alguna la autoridad y responsabilidad del Consejo conforme a la presente Carta para ejercer en cualquier momento la acción que estime necesaria con el fin de mantener o restablecer la paz y la seguridad internacionales.

22 Caso del Canal de Corfú, Reino Unido de Gran Bretaña vs. Albania-Méritos, sentencia del 9 de abril de 1949, p. 32, de la Corte Internacional de Justicia, en http://www. icj-cij.org/icjwww/icases/icc/icc_ijudgment/iCC_ijudgment_19490409.pdf. 
Este artículo, que recoge el derecho internacional consuetudinario, no hace más que reconocer el derecho de autotutela o autoayuda que tienen todos los Estados soberanos; sin embargo, para algunos autores ${ }^{23} \mathrm{su}$ interpretación debe ser restrictiva ya que sólo hace referencia a la respuesta ante un ataque armado y no ante otras situaciones como la amenaza de la paz. "Se trata así de una medida de carácter perentorio pero provisional y en tanto no accione la comunidad internacional las medidas de tipo colectivo que tiene previstas". ${ }^{24}$

Actuar en legítima defensa implica, entonces, un ataque armado previo, sin embargo, el 14 de diciembre de 1974, la Asamblea General adoptó por consenso la resolución 3314 (XXIX) sobre la definición de agresión, en cuyo artículo 2o. se indica que:

El primer uso de la fuerza armada por un Estado en contravención de la Carta constituirá prueba prima facie de un acto de agresión, aunque el Consejo de Seguridad puede concluir, de conformidad con la Carta, que la determinación de que se ha cometido un acto de agresión no estaría justificada a la luz de otras circunstancias pertinentes, incluido el hecho de que los actos de que se trata o sus consecuencias no son de suficiente gravedad.

Para Diez de Velasco, ${ }^{25}$ esta disposición admite la legítima defensa preventiva, pues reconoce que en algunos casos el primer uso de la fuerza no sea un acto de agresión, pero en definitiva, según la resolución, la cuestión de si ha cometido un acto de agresión queda en manos del Consejo de Seguridad.

La acción militar de Estados Unidos en Irán llevada a cabo entre el 24 y 25 de abril de 1980 para liberar a su personal diplomático y consular que estaban tomados como rehenes en su propia embajada en Teherán, fue justificada por el entonces presidente estadounidense, James Carter, como una intervención humanitaria, dados los riesgos existentes

23 Como Carrillo Salcedo, Juan Antonio, Curso de derecho internacional público, Madrid, Tecnos, 1994, p. 327.

24 Rodríguez Carrión, Alejandro, Uso de la fuerza por los Estados. Interacción entre política y derecho: algunos problemas, Málaga, Organización Sindical, 1974, p. 56.

25 Diez de Velasco, op. cit., nota 16, p. 851. 
para los rehenes, legitimada en última instancia como ejercicio del derecho de legítima defensa por parte de los Estados Unidos de América. ${ }^{26}$

Al no existir ataque armado previo, podría pensarse que no se encuadra como legítima defensa

aunque sí una intervención limitada, necesaria y proporcionada, y justificada como contramedida del Estado víctima respecto del ilícito previo imputable a la República Islámica de Irán, responsable internacionalmente del secuestro de personas internacionalmente protegidas cuyas vidas se encontraban seriamente amenazadas. ${ }^{27}$

Lamentablemente, la Corte Internacional de Justicia, que estaba viendo el caso concerniente al personal diplomático y consular de Estados Unidos en Teherán (Estados Unidos vs. Irán 1979-1981), no se pronunció sobre el tema de fondo.

La legítima defensa no sólo puede ser individual, sino colectiva, así lo indica el artículo 51 de la Carta de la ONU. Sin embargo, debemos hacer algunas precisiones con relación a ello.

En el caso concerniente a las actividades militares y paramilitares en y contra Nicaragua, Estados Unidos expuso que su actuación fue con base en el artículo 51 de la Carta, en otras palabras, el derecho de autodefensa colectiva.

Sin embargo la Corte sentenció que no puede justificarse como legítima defensa colectiva conductas hostiles si los Estados agraviados no la requirieron:

Está también claro que es el Estado que es la víctima de un ataque armado debe formar y declarar la opinión de que ha sido atacado. No hay ninguna regla en el derecho internacional consuetudinario permitiendo que otro Estado ejercite el derecho de la autodefensa colectiva en base de su propia valoración de la situación. Donde la autodefensa colectiva es invocada, es esperado que el Estado para cuyo beneficio es usado este derecho habrá declarado él mismo ser víctima de un ataque armado... ${ }^{28}$

26 Véase Carrillo Salcedo, op. cit., nota 23, p. 328.

27 Idem.

28 Caso concerniente a las Actividades militares y paramilitares en y contra Nicaragua-Méritos, sentencia del 27 de junio de 1986, párrafo 195, de la Corte Internacional de Justicia. 
Es también evidente que si el Estado víctima desea que otro Estado venga a su ayuda en el ejercicio del derecho de la autodefensa colectiva, normalmente hará una solicitud expresa en tal efecto... ${ }^{29}$

\section{B. Condiciones de ejercicio de la legítima defensa}

El ejercicio de la legítima defensa debe cumplir ciertas condiciones que "se derivan de la práctica inveterada de los Estados - necesidad, proporcionalidad e inmediatez-; otras corresponden a su articulación con el sistema de seguridad colectiva — provisionalidad y subsidiariedad-". 30

Para graficar la condición del estado de necesidad y proporcionalidad es usual citar el caso del Carolina (1837), entre Estados Unidos y Gran Bretaña.

El Caroline, buque bajo pabellón estadounidense que suministraba ayuda a rebeldes canadienses contra Gran Bretaña, fue destruido - con pérdidas de vidas humanas - el 30 de diciembre de 1837 por los británicos cuando se encontraba fondeado en aguas de los Estados Unidos. Los británicos justificaron el hecho como legítima defensa. En respuesta, Daniel Webster, secretario de Estado de Estados Unidos, expuso que para que el recurso a la legítima defensa fuera admisible, el país afectado debía demostrar "una necesidad de legítima defensa instantánea, irresistible, que no permitiera la opción de otros medios y no dejara momento alguno de deliberación". 31

En otras palabras, la necesidad indica que éste será el único medio a recurrir. La proporcionalidad incluye la magnitud de la fuerza a utilizar.

Hay que recordar que la CIJ se planteó, en el asunto sobre la legalidad de la amenaza o el uso de armas nucleares (1996), si la condición de proporcionalidad haría ilegal un ejercicio de la legítima defensa basado en la utilización de armas nucleares, concluyendo que para que un ejercicio proporcional de la legítima defensa sea lícito debe cumplir también con los requerimientos del derecho aplicable a los conflictos armados. ${ }^{32}$

29 Ibidem, párrafo 232.

30 Remiro Brotóns, Antonio et al., Derecho internacional, Madrid, McGraw-Hill, 1997, p. 921.

31 Ibidem, pp. 922 y 923.

32 Ibidem, p. 922. 
Otra condición que se deriva del artículo 51 es la inmediatez, esto en concordancia con el artículo 2o., párrafo 4, sobre prohibición del uso de la fuerza.

Las condiciones de provisionalidad y subsidiariedad significan que las medidas tomadas en ejercicio del derecho de legítima defensa tanto individual como colectiva, serán comunicadas inmediatamente al Consejo de Seguridad, según lo indica el artículo 51 de la Carta de las Naciones Unidas.

\section{Uso de la fuerza contra Estados enemigos}

A pesar de los años, todavía existe en la Carta de la Organización de las Naciones Unidas la mención a los "Estados enemigos". ${ }^{33}$

Esta frase de la Carta hace referencia a las "Potencias del Eje", Alemania, Italia y Japón, que perdieron la Segunda Guerra Mundial contra los aliados, y sin embargo ahora son miembros de las Naciones Unidas, inclusive algunos han formado parte del Consejo de Seguridad como miembros no permanentes.

Así, el artículo 53 de la Carta indica que:

1. El Consejo de Seguridad utilizará dichos acuerdos u organismos regionales, si a ello hubiere lugar, para aplicar medidas coercitivas bajo su autoridad. Sin embargo, no se aplicarán medidas coercitivas en virtud de acuerdos regionales o por organismos regionales sin autorización del Consejo de Seguridad, salvo que contra Estados enemigos, según se les define en el párrafo 2 de este artículo, se tomen las medidas dispuestas en virtud del artículo 107 o en acuerdos regionales dirigidos contra la renovación de una política de agresión de parte de dichos Estados, hasta tanto que a solicitud de los gobiernos interesados quede a cargo de la organización la responsabilidad de prevenir nuevas agresiones de parte de aquellos Estados.

2. El término "Estados enemigos" empleado en el párrafo 1 de este artículo se aplica a todo Estado que durante la Segunda Guerra Mundial haya sido enemigo de cualquiera de los signatarios de esta Carta.

33 La Carta de las Naciones Unidas, artículo 52, párrafo 2, prescribe que "el término Estados enemigos empleado en el párrafo 1 de este artículo se aplica a todo Estado que durante la segunda guerra mundial haya sido enemigo de cualquiera de los signatarios de esta Carta". 
De la misma manera el artículo 107 prescribe que:

Ninguna de las disposiciones de esta Carta invalidará o impedirá cualquier acción ejercida o autorizada como resultado de la Segunda Guerra Mundial con respecto a un Estado enemigo de cualquiera de los signatarios de esta Carta durante la citada guerra, por los gobiernos responsables de dicha acción.

Si bien es cierto que al final de la segunda gran guerra eran de vital importancia estos artículos, ahora están desfasados y deben ser modificados, ya que en teoría cualquier Estado podría accionar contra los "Estados enemigos" cumpliendo ciertos requisitos que hoy por hoy son imposibles.

\section{Medidas coercitivas de las Naciones Unidas}

Las Naciones Unidas, por intermedio del Consejo de Seguridad podrán utilizar medidas coercitivas ante situaciones que éste crea conveniente, en aplicación del capítulo VII de la Carta.

Ejemplo de medidas coercitivas que puedan ser consideradas uso de la fuerza, mas no implican una agresión directa, son los bloqueos navales.

\section{E. Uso de la fuerza autorizado por las Naciones Unidas}

En primer lugar el Consejo de Seguridad podrá utilizar la fuerza armada, en caso de quebrantamiento de la paz o acto de agresión, según lo estimare conveniente, como lo indica la Carta de las Naciones Unidas, artículo 42:

Si el Consejo de Seguridad estimare que las medidas de que trata el artículo $41^{34}$ pueden ser inadecuadas o han demostrado serlo, podrá ejercer, por medio de fuerzas aéreas, navales o terrestres, la acción que sea necesaria

34 La Carta de las Naciones Unidas, en su artículo 41, otorga al Consejo de Seguridad las facultades para "decidir qué medidas que no impliquen el uso de la fuerza armada han de emplearse para hacer efectivas sus decisiones, y podrá instar a los miembros de las Naciones Unidas a que apliquen dichas medidas, que podrán comprender la interrupción total o parcial de las relaciones económicas y de las comunicaciones ferroviarias, marítimas, aéreas, postales, telegráficas, radioeléctricas, y otros medios de comunicación, así como la ruptura de relaciones diplomáticas". 
para mantener o restablecer la paz y la seguridad internacionales. Tal acción podrá comprender demostraciones, bloqueos y otras operaciones ejecutadas por fuerzas aéreas, navales o terrestres de miembros de las $\mathrm{Na}-$ ciones Unidas.

Este artículo debe ser concordado con la Carta de las Naciones Unidas, artículo 39 que señala que es el propio consejo el que determinará la existencia de una amenaza a la paz o acto de agresión:

El Consejo de Seguridad determinará la existencia de toda amenaza a la paz, quebrantamiento de la paz o acto de agresión y hará recomendaciones o decidirá qué medidas serán tomadas de conformidad con los artículos 41 y 42 para mantener o restablecer la paz y la seguridad internacionales.

La primera vez que el Consejo de Seguridad autorizó a una coalición de Estados el uso de la fuerza fue en la guerra de Corea. Otro caso paradigmático fue la autorización del uso de la fuerza a una coalición de Estados ante la invasión de Irak por Kuwait.

Por otro lado, la Carta de las Naciones Unidas, artículo 52, párrafo 1, prescribe que:

El Consejo de Seguridad utilizará dichos acuerdos u organismos regionales, si a ello hubiere lugar, para aplicar medidas coercitivas bajo su autoridad. Sin embargo, no se aplicarán medidas coercitivas en virtud de acuerdos regionales o por organismos regionales sin autorización del Consejo de Seguridad, salvo que contra Estados enemigos...

Entonces, el Consejo de Seguridad podrá autorizar a un organismo regional a usar la fuerza en cumplimiento de su mandato de mantener la paz y seguridad internacionales.

\section{Uso legítimo de la fuerza no previsto en la Carta} de las Naciones Unidas

Existen otras formas de uso de la fuerza que aún no estando previstas en la Carta de las Naciones Unidas son consideradas legítimas por el derecho internacional general. A continuación las desarrollamos. 
A. Uso legítimo de la fuerza de los pueblos que luchan por su libre determinación: guerras de liberación nacional (Protocolo I Adicional a las Convenciones de Ginebra, 1977)

A pesar que el derecho internacional no ha definido con claridad el término "pueblo", el Protocolo I a las Convenciones de Ginebra de 1977 ha regulado las luchas que ellos tienen contra la dominación colonial, la ocupación extranjera y los regímenes racistas.

La expresión "dominación colonial" implica el caso en que un pueblo ha tenido que tomar las armas para liberarse de la dominación de otro pueblo. ${ }^{35}$ Tal es el caso del pueblo Saharaui que enfrentó de 1975 a 1991 un sangriento enfrentamiento contra la ocupación colonial del Reino de Marruecos y que todavía no encuentra solución a pesar de la intervención de las Naciones Unidas.

La expresión "ocupación extranjera" cubre los casos de ocupación parcial o total de un territorio que aún no está plenamente constituido en Estado. ${ }^{36}$ Como es el caso de la invasión israelí al territorio palestino desde 1948 hasta la fecha.

Por último, la expresión "regímenes racistas" implica si no la existencia de dos pueblos distintos, por lo menos una separación que garantiza, en el seno de un pueblo, la hegemonía de una parte de éste según una concepción racial. ${ }^{37}$ Como lo fue el caso del gobierno racista de Rhodesia, cuyo régimen racista fue duramente criticado a nivel internacional a tal punto de ser declarado como una amenaza a la paz y seguridad internacionales por el Consejo de Seguridad. ${ }^{38}$

La regulación de este tipo de conflictos tiene su basamento en el principio de libre determinación de los pueblos, que tiene sus raíces en la Revolución francesa de 1789 y la Ilustración. De un principio europeo se convirtió en universal a causa del proceso histórico de la descolonización. Su fuerza legitimadora es tan grande que muchas comunidades hu-

35 Cfr. Sandoz, Yves et al., Comentario del Protocolo del 8 de junio de 1977 adicional a los Convenios de Ginebra del 12 de agosto de 1949 relativo a la protección de las víctimas de los conflictos armados internacionales (Protocolo I), Bogotá, CICR, Plaza \& Janés, 2000, t. II, p. 87.

36 Idem.

37 Idem.

38 Resolución CS 232 (1966), aprobada en la 1340a. sesión, del 16 de diciembre de 1966. 
manas invocan dicho principio para justificar su recurso al empleo de la violencia e incluso del terrorismo. ${ }^{39}$

\section{B. Uso de la fuerza en guerras civiles no incluidas en el Protocolo I Adicional a las Convenciones de Ginebra (1977)}

Una guerra civil es una guerra entre dos o más grupos de habitantes del mismo Estado. Puede ser llevada a cabo para controlar el gobierno de un Estado o causada por el deseo de una parte de la población de separarse y formar un nuevo Estado. ${ }^{40}$

Estos dos tipos de guerras civiles son las más comunes, sin embargo, pueden existir otros tipos, por ejemplo: los rebeldes pueden tratar de forzar a los gobernantes a efectuar concesiones, como consentir autonomías regionales. Es también posible que una guerra civil sea llevada a cabo entre facciones mientras el gobierno queda neutral o impotente. ${ }^{41}$

En vista que la Carta de las Naciones Unidas, artículo 2o., párrafo 4, prohíbe el uso de la fuerza sólo en las relaciones internacionales de los Estados, es evidente que un Estado soberano tiene el derecho de uso de la fuerza cuando sucede una guerra civil que no se encuentre incluida en el Protocolo I Adicional a las Convenciones de Ginebra (1977).

Es decir, tiene derecho a defender su territorio incluso de las amenazas internas no legítimas; sin embargo, el Estado debe respetar a cabalidad el derecho internacional humanitario.

Entonces, si la guerra civil se establece como una guerra de liberación nacional, y por tanto, obtiene una dimensión internacional, el Estado debe abstenerse de recurrir a cualquier medida de fuerza que prive a los pueblos al ejercicio de su derecho a la libre determinación, a la libertad o a la independencia.

\section{Uso de la fuerza en conflictos internos}

A pesar de los pactos internacionales de Derechos Civiles y Políticos y de Derechos Económicos, Sociales y Culturales del 16 de diciembre de 1966, auspiciados por Naciones Unidas y las declaraciones de la Asam-

39 Carrillo Salcedo, op. cit., nota 23, p. 32.

40 B. Akehurst, Michael, "Civil War", en Bernhardt, R. (ed.), Encyclopedia of Public International Law, 1992, vol. I, p. 597.

41 Idem. 
blea General de las Naciones Unidas contenidas en la resolución 1514 (XV) "declaración sobre la concesión de la independencia a los países y pueblos coloniales", del 14 de diciembre de 1960, y la resolución 2625 (XXV) "declaración sobre los principios de derecho internacional referente a las relaciones de amistad y a la cooperación entre los Estados de conformidad con la Carta de las Naciones Unidas", del 24 de octubre de 1970, que afirman que todos los pueblos tienen el derecho de libre determinación, este principio no se ha convertido en una regla absoluta de obligatorio cumplimiento en el derecho internacional.

Es decir, el principio de libre determinación de los pueblos sólo puede invocarse en ciertas circunstancias que están estipuladas en el Protocolo I (1977) a las Cuatro Convenciones de Ginebra de 1949, sobre las guerras de liberación nacional. Es decir, se aplica a los pueblos que luchan contra la dominación colonial, la ocupación extranjera y los regímenes racistas.

Más bien, se afirma que si hay un principio firmemente asentado en los instrumentos mencionados es el de la integridad territorial del Estado. Así es una regla de derecho internacional la prohibición del uso de la fuerza contra la integridad de los Estados y sería un acto de intervención internacional ilícito prestar asistencia a movimientos separatistas. ${ }^{42}$

En el caso de las Islas Aaland (1921), sobre independencia de dichas islas de Finlandia, la comisión de relatores especiales designados por la Liga de las Naciones, afirmó que la soberanía de éstas pertenece a Finlandia, ${ }^{43}$ además, la comisión afirmó que:

La separación de una minoría del Estado de que forma parte... (sic) puede solamente considerarse como una solución excepcional, un último recurso cuando un Estado no demuestra tener voluntad o capacidad para establecer y aplicar garantías justas y efectivas. ${ }^{44}$

Entonces, de este caso se puede deducir que el principio de autodeterminación o libre determinación de los pueblos, no es una regla de derecho internacional. ${ }^{45}$

42 Remiro Brotóns, op. cit., nota 30, p. 129.

43 Modeen, Tore, "Aaland Islands", en Bernhardt, R. (ed.), op. cit., nota 40, p. 2.

44 Remiro Brotóns, op. cit., nota 30, p. 129.

45 Shaw, Malcom, N., International Law, Cambridge, Cambridge University Press, 1997, p. 177. 
Como ejemplos más modernos se encuentran el caso del pueblo bengalí, que obtuvo su independencia de Paquistán en 1971, con el nombre de Bangladesh, porque se sentían discriminados y explotados. En contraste se encuentra la República Turca del Norte de Chipre, que sólo es reconocida por Turquía, que proclamó su independencia en 1983, creada sólo como consecuencia de la invasión turca de $1974 .{ }^{46}$

$a$. Uso de la fuerza contra la insurgencia que no esté incluida en el Protocolo I Adicional a las Convenciones de Ginebra (1977)

Un grupo insurgente no es sujeto de derecho internacional hasta que cumpla con las condiciones de subjetividad tales como "establecer un control estable sobre parte del territorio bajo una autoridad organizada" ${ }^{47}$ Caso contrario, su actividad será, entonces, "regulada por el derecho interno del Estado en que la insurgencia tiene lugar. El Estado puede adoptar, para eliminar dicha insurrección, todas las medidas que pone a su disposición su ordenamiento jurídico: estado de emergencia, ley marcial, estado de sitio, etcétera". ${ }_{48}$

Sin embargo, si los grupos denominados insurgentes luchan por una causa legítima ya planteada líneas arriba (lucha contra la dominación colonial o los regímenes racistas), los Estados tendrían prohibido usar la fuerza contra ellos.

\section{$b$. Uso de la fuerza contra el separatismo}

Una lucha separatista podría ser la consecuencia de la falta de autonomía de una región dentro de un Estado, pero la autonomía no es un principio del derecho internacional, menos aún se deriva del principio de

46 Revilla Montoya, Pablo César, "Chechenia: ¿separatismo, terrorismo o libre determinación de los pueblos?", Revista de Investigación Jurídica Docentia et Investigatio, Lima, núm. 1, noviembre de 2005, vol. 7, p. 191.

47 Mosler, Herman, "Subjects of International Law", en Bernhardt, R. (ed.), op. cit., nota 40 , vol. IV, p. 724.

48 Cfr. Barberis, Julio et al., Sujetos del derecho internacional, Buenos Aires, Ábaco de Rodolfo Depalma, 1998, p. 116. 
Tabla. Uso de la fuerza en conflictos internos

\begin{tabular}{|c|c|}
\hline $\begin{array}{c}\text { Los Estados pueden usar la fuerza } \\
\text { en los siguientes casos }\end{array}$ & $\begin{array}{c}\text { Los insurgentes pueden usar la fuerza } \\
\text { en los siguientes casos }\end{array}$ \\
\hline $\begin{array}{l}\text { - Separatismo/guerras civiles } \\
\text { - Si los insurgentes violan los DDHH }\end{array}$ & $\begin{array}{l}\text { - Guerra de liberación nacional } \\
\text { - Si las autoridades violan } \\
\text { masivamente los DDHH }\end{array}$ \\
\hline $\begin{array}{l}\text { Los Estados tiene las siguientes } \\
\text { prohibiciones }\end{array}$ & $\begin{array}{c}\text { Los insurgentes tienen las siguientes } \\
\text { prohibiciones }\end{array}$ \\
\hline $\begin{array}{l}\text { - Contra una guerra de liberación } \\
\text { nacional } \\
\text { - Violaciones de los DDHH }\end{array}$ & $\begin{array}{l}\text { - Violaciones de los DDHH } \\
\text { - Si buscan instaurar un régimen } \\
\text { violador de los DDHH }\end{array}$ \\
\hline
\end{tabular}

FUENTE: Elaborado por el autor.

autodeterminación, ${ }^{49}$ o libre determinación; sin embargo, la autonomía es un mecanismo que utilizan y deben utilizar los Estados para solucionar una controversia interna que podría devenir en separatismo.

Lo cierto es que no existe una regla de derecho internacional que obligue a los Estados a otorgar autonomía a sus minorías (étnicas, religiosas o de otra índole), esto es con base en el principio de no intervención en los asuntos internos de los Estados estipulado en el artículo 2o., párrafo 7, de la Carta de las Naciones Unidas. Aunque la consecuencia directa de una buena autonomía es el mantenimiento de la paz, al menos temporalmente.

Sin embargo, existen dos supuestos en los que existiría un derecho de separación. Uno, es el de la población de un territorio anexionado por un Estado mediante el uso de la fuerza prohibido por el derecho internacional (como el pueblo de Palestina). El otro supuesto se daría cuando un Estado violase los derechos de un pueblo, ejecutando o consintiendo su

49 Cfr. Thürer, Daniel, "Self-determination", en Bernhardt, R. (ed.), op. cit., nota 40, vol. IV, p. 369. El autor afirma que la autodeterminación como principio tiene alcance universal, y debe ser desarrollado en el sentido del proceso continuado de la autonomía interna, es decir, gobierno democrático y la protección de minorías (étnicas) dentro de Estados existentes. 
genocidio, discriminándolo políticamente de forma grave y sistemática o destruyendo su identidad..$^{50}$

Finalmente, podemos indicar que a pesar de que un conflicto interno basado sólo en el separatismo se internacionalice por medio de la intromisión de otro Estado a favor de los separatistas y éstos proclamen un nuevo Estado, el Estado afectado tiene el derecho del uso legítimo de la fuerza. Caso concreto podemos citar que en 1931, luego de la segunda guerra chino-japonesa, Manchuria fue conquistada por Japón, que la declaró estado independiente en 1932 bajo el nombre de Manchukuo.

\section{Breve balance del uso de la fuerza}

Si bien es cierto que la Carta de las Naciones Unidas prescribe reglas de obligatorio cumplimiento sobre el empleo de la fuerza armada, no son suficientes ante situaciones límite como el genocidio o las violaciones masivas y sistemáticas de los derechos humanos que devengan en graves crisis humanitarias como en el caso de Darfur.

De la misma manera, aunque existen otras formas de uso de la fuerza legítimas contempladas en el derecho internacional general, éste no ha dado una salida clara sobre cómo actuar ante casos similares al de Darfur.

\section{LA INTERVENCIÓN HUMANITARIA, LA RESPONSABILIDAD DE PROTEGER Y LA SEGURIDAD HUMANA}

En este apartado explicaremos las diferentes doctrinas jurídicas que buscan una solución a las violaciones masivas y sistemáticas de los derechos humanos que devienen en crisis humanitarias. Adelantamos nuestra posición a favor de la doctrina de la responsabilidad de proteger, que recoge fundamentos jurídicos para intervenir militarmente, pero que en algunos casos no se ajustan a los mecanismos jurídicos existentes en el sistema mundial actual.

\section{La intervención humanitaria}

Para Holzgrefe, la intervención humanitaria es la amenaza o el uso de la fuerza, a través de las fronteras estatales, por un Estado (o grupo de 
Estados), destinado a prevenir o acabar con las violaciones graves y generalizadas de los derechos humanos fundamentales de individuos excepto sus propios ciudadanos, sin el permiso del Estado dentro de cuyo territorio es aplicada la fuerza. ${ }^{51}$

Sin embargo, desde un punto de vista estricto, la intervención humanitaria contempla el uso proscrito de la fuerza militar, por tanto ilegal según las Carta de la ONU (salvo excepciones como autorización del Consejo de Seguridad). Por otro lado, esta intervención militar no contempla un plan pos-intervención.

\section{La doctrina de la responsabilidad de proteger y la seguridad humana}

Esta novísima doctrina fue elaborada por Comisión Internacional sobre Intervención y Soberanía de los Estados, convocada por el gobierno de Canadá un año después de la crisis provocada por la invasión de la OTAN en Kosovo y ante la pregunta que realizó el entonces secretario general de las Naciones Unidas, Kofi Annan, en su discurso ante la Asamblea del Milenio, sobre "¿cómo... responder a situaciones como las de Rwanda o Srebrenica y a las violaciones graves y sistemáticas de los derechos humanos que transgreden todos los principios de nuestra humanidad común?". 52

La doctrina de la responsabilidad de proteger contempla una nueva visión de la seguridad internacional, así:

El debate sobre la seguridad se desplaza desde la seguridad territorial y la seguridad basada en el armamento hacia la seguridad basada en el desarrollo humano y el acceso a la alimentación, el empleo y la seguridad ambiental. Los componentes básicos de la seguridad humana (enfatizado por nosotros) - la seguridad de las personas frente a las amenazas contra la vida, la salud, los medios de subsistencia, la seguridad personal y la dignidad humana - pueden verse en peligro debido a una agresión externa pero

51 Holzgrefe, J. L., "The Humanitarian Intervention Debate”, en Holzgrefe, J. L. y Keohane, Robert O. (eds.), Humanitarian Intervention: Ethical, Legal And Political Dilemmas, Cambridge, Cambridge University Press, 2003, p. 18.

52 A/54/2000, "We the Peoples: the Role of the United Nations in the Twenty-First Century", 27 de marzo de 2000, p. 35. 
también a factores internos, incluidas las fuerzas de "seguridad" de un país. ${ }^{53}$

Según la doctrina de la responsabilidad de proteger, basada en la soberanía, todos los Estados soberanos tienen la responsabilidad primordial de proteger a la población bajo su jurisdicción; sin embargo, las Naciones Unidas la adquieren si los Estados no pueden o no quieren asumirla:

Dicha responsabilidad consiste en prevenir, reaccionar y reconstruir. Sin embargo, cuando en un conflicto se evidencia una grave crisis humanitaria, y las pérdidas humanas y la limpieza étnica son patentes, así como las violaciones masivas al ius cogens, se podría efectuar una intervención militar, que debe ser solicitada al Consejo de Seguridad de las Naciones Unidas, como autoridad competente, este último debe examinar sin demora el caso, al mismo tiempo que los Estados con derecho a veto renuncian a él, siempre y cuando no se violenten sus intereses vitales. En el caso extremo que exista un rechazo de la solicitud o una visible demora del examen en el Consejo de Seguridad, se deberá recurrir a la Asamblea General o a la acción de las Organizaciones Regionales, que pueden solicitar la autorización posterior al Consejo de Seguridad. ${ }^{54}$

Como podemos apreciar, la doctrina de la responsabilidad de proteger, basada en la seguridad humana, es un gran avance en la protección de los derechos humanos ante graves crisis humanitarias; empero, mientras el Consejo de Seguridad, único ente acreditado por la comunidad internacional para usar o autorizar la fuerza militar, se encuentre inactivo a causa del derecho de veto que ostentan las grandes potencias, otros Estados u organismos internacionales podrían autoatribuirse dicha prerrogativa, generando así una grave crisis en el sistema internacional.

Por tales motivos y otros del tipo político, no existe unanimidad en la comunidad internacional para aceptar la doctrina de la responsabilidad de proteger.

53 Comisión Internacional sobre Intervención y Soberanía de los Estados (CIISE), "La responsabilidad de proteger", informe de la CIISE, diciembre de 2001, pp. 15 y 16, http://www.iciss.ca/pdf/Spanish-report.pdf

54 Revilla Montoya, Pablo César, "Hacia la responsabilidad de proteger. Bases jurídicas para una respuesta colectiva ante crisis humanitarias", Anuario Mexicano de Derecho Internacional, vol. III, 2007, p. 673. 
Sin embargo, sus lineamientos básicos fueron acogidos por el informe del grupo de alto nivel, que fue convocado por el entonces secretario general de las Naciones Unidas, Kofi Annan y su informe "Un concepto más amplio de la libertad: desarrollo, seguridad y derechos humanos para todos" (21 de marzo de 2005).

Asimismo, el Acta Final de la Cumbre Mundial 2005, aprobada por la Asamblea General de las Naciones Unidas señaló entre otras cosas que:

La comunidad internacional, por medio de las Naciones Unidas, tiene también la responsabilidad de utilizar los medios diplomáticos, humanitarios y otros medios pacíficos apropiados, de conformidad con los capítulos VI y VIII de la carta, para ayudar a proteger a las poblaciones del genocidio, los crímenes de guerra, la depuración étnica y los crímenes de lesa humanidad. En este contexto, estamos dispuestos a adoptar medidas colectivas, de manera oportuna y decisiva, por medio del Consejo de Seguridad, de conformidad con la carta, incluido su capítulo VII, en cada caso concreto y en colaboración con las organizaciones regionales pertinentes cuando proceda, si los medios pacíficos resultan inadecuados y es evidente que las autoridades nacionales no protegen a su población del genocidio, los crímenes de guerra, la depuración étnica y los crímenes de lesa humanidad. ${ }^{55}$

En general, podemos afirmar que los Estados a favor de la doctrina de la responsabilidad de proteger están encabezados por Canadá y aquellos que invocan a la seguridad humana como parte de política exterior, mientras los que están en contra están encabezados por Venezuela y aquellos que entienden esta doctrina como una excusa para la intervención en los asuntos internos de los Estados.

\section{LAS NACIONES UNIDAS Y EL CONFLICTO EN SUDÁN-DARFUR}

\section{Actuación de las Naciones Unidas en Darfur}

En Darfur se evidencia una crisis humanitaria que las Naciones Unidas no han sabido manejar. Como es costumbre, las Naciones Unidas han

55 A/RES/60/1, documento final de la Cumbre Mundial 2005, 24 de octubre de 2005, párr. 139 . 
llegado tarde al conflicto y no han podido anticipar ni frenar la catástrofe humanitaria.

Sin embargo, hay que tomar en cuenta la reticencia del gobierno sudanés a aceptar una operación de paz de la ONU, tal vez por el miedo a que algunas de sus autoridades tengan de ser llevadas a la Corte Penal Internacional por cometer crímenes de guerra o de lesa humanidad, incluso algunos ${ }^{56}$ afirman que se ha cometido genocidio en esa convulsionada región.

La primera resolución del Consejo de Seguridad que hace referencia a la situación en Darfur fue la resolución 1547 (2004), en ella se indica que:

Hace suyas las conclusiones del secretario general sobre la situación imperante en el Sudán, en particular en Darfur y en el alto Nilo, que se enuncian en el párrafo 22 de su informe, insta a las partes a utilizar su influencia para detener de inmediato los enfrentamientos en la región de Darfur, en el alto Nilo y en otros lugares, exhorta a las partes en el Acuerdo de Cesación del Fuego de Ndjamena, de 8 de abril de 2004, a concertar sin demora un acuerdo político. ${ }^{57}$

El secretario general había presentado un informe al Consejo de Seguridad luego de la declaración de su presidente, ${ }^{58}$ en la que se le pedía que iniciara la labor preparatoria para determinar la mejor forma en que las Naciones Unidas podrían prestar su pleno apoyo a la aplicación de un acuerdo global de paz entre el gobierno de Sudán y el Movimiento-Ejército de Liberación del Pueblo Sudanés.

Entre sus observaciones finales, el secretario general indicó que "la situación catastrófica que atraviesa Darfur constituye un problema que dificultará considerablemente la aplicación de un acuerdo de paz en el

56 Como Nso, Sara, "La crisis de Darfur y el futuro de la seguridad africana", UNISCI Discussion Papers, octubre de 2004, p. 2, http://www.ucm.es/BUCM/revistas/cps/16962206/articulos/UNIS0404330020A.PDF

57 S/RES/1547 (2004), aprobada por el Consejo de Seguridad en su 4988a. sesión, celebrada el 11 de junio de 2004, párrafo 6.

58 S/PRST/2003/16, declaración del presidente del Consejo de Seguridad, del 10 de octubre de 2003. 
Sudán. Para el éxito del futuro papel de las Naciones Unidas, es fundamental llegar a un acuerdo significativo sobre Darfur". ${ }^{59}$

Más adelante, el Consejo de Seguridad emitió su resolución 1556 $(2004)^{60}$ determinando que la situación en el Sudán constituye una amenaza para la paz y la seguridad internacionales.

Asimismo, apoyó el despliegue de observadores internacionales y la fuerza de protección de la Unión Africana, en la región de Darfur. También exigió que el gobierno de Sudán cumpla sus compromisos de desarmar a las milicias janjaweed y aprehender y procesar a los líderes janjaweed y sus asociados, que hayan incitado y llevado a cabo violaciones de los derechos humanos y del derecho internacional humanitario y otras atrocidades.

Igualmente, decidió que todos los Estados adopten las medidas necesarias para impedir la venta o el suministro de armas a todas las entidades no gubernamentales y los particulares que realicen actividades en Darfur. De la misma forma, pidió al secretario general que preste asistencia a la Unión Africana en la planificación y las evaluaciones para su misión en Darfur.

En ese mismo año, el Consejo de Seguridad pidió al secretario general que establezca una comisión internacional que investigue todas las denuncias de transgresiones del derecho internacional humanitario y las normas de derechos humanos cometidas en Darfur por todas las partes, y que constate también si se han producido o no actos de genocidio e identifique a los autores de tales transgresiones a fin de que los responsables rindan cuentas de sus actos. ${ }^{61}$

Cuando el Consejo de Seguridad crea la Misión de las Naciones Unidas en el Sudán (UNMIS), el 24 marzo de 2005, le pidió que mantenga una coordinación y un enlace continuos y estrechos a todos los niveles con la Misión de la Unión Africana en el Sudán (AMIS) con miras a afianzar rápidamente la labor de promoción de la paz en Darfur, pero no le otorgó más poderes.

59 S/2004/453, informe del secretario general sobre Sudán, del 3 de junio de 2004, párrafo 22 .

60 S/RES/1556 (2004), aprobada por el Consejo de Seguridad en su 5015a. sesión, celebrada el 30 de julio de 2004.

61 Véase S/RES/1564 (2004), aprobada por el Consejo de Seguridad en su 5040a. sesión, celebrada el 18 de septiembre de 2004, párrafo 12 . 
Sin embargo, en vista de que las partes en el conflicto no cumplían con sus resoluciones, el Consejo de Seguridad, en su resolución 1591 (2005), del 29 de marzo de 2005, creó un Comité del Consejo de Seguridad, integrado por todos sus miembros, para que vigile el cumplimiento de sus decisiones.

Por otro lado, el 31 de marzo de 2005, tomando nota del informe de la Comisión Internacional de Investigación sobre las transgresiones del derecho internacional humanitario y las normas de derechos humanos en Darfur (S/2005/60), el Consejo de Seguridad decidió remitir la situación en Darfur desde el 1o. de julio de 2002 al fiscal de la Corte Penal Internacional. ${ }^{62}$

Lamentablemente, la situación en Darfur no cambió a pesar de los esfuerzos mostrados por la Unión Africana. En ese contexto, el Consejo de Seguridad, en su resolución 1663 (2006), del 24 de marzo de 2006, acogió con beneplácito el comunicado emitido el 10 de marzo de 2006 por el Consejo de Paz y Seguridad de la Unión Africana en su 46a. reunión, y su decisión de apoyar en principio la transición de la AMIS a una operación de las Naciones Unidas y prorrogar el mandato de la AMIS hasta el 30 de septiembre de 2006.

El 25 de abril de 2006, el Consejo de Seguridad prohibió viajar al extranjero y el congelamiento de sus activos fuera de su país a cuatro sudaneses acusados de cometer violaciones a los derechos humanos en Darfur, así como de obstaculizar el proceso de paz en esa región del occidente del país africano. ${ }^{63}$

Luego de tres años de conflicto interno, y tras la firma del Acuerdo de Paz de Darfur, ${ }^{64}$ el Consejo de Seguridad, mediante su resolución

62 S/RES/1593 (2005), aprobada por el Consejo de Seguridad en su 5158a. sesión, celebrada el 31 de marzo de 2005.

63 S/RES/1672 (2006), aprobada por el Consejo de Seguridad en su 5423a. sesión, celebrada el 25 de abril de 2006. Los sancionados por el Consejo fueron el general del Ejército sudanés, Gaffar Mohamed Elhassan; el jefe de la tribu Jalul, Musa Hilal; el comandante del Ejército de Liberación de Sudán (MLS), Adam Yacub Shant; y el líder de la milicia progubernamental Movimiento Nacional Pro Reforma y Desarrollo, Gabril Abdil Karim Badri.

64 El Acuerdo de Paz de Darfur se firmó el 5 de mayo de 2006; sus signatarios fueron el gobierno de Sudán y una de las facciones rebeldes del Ejército de Liberación de Sudán, encabezada por Minni Minawi (del grupo étnico zaghawa). Otras facciones del Ejército de Liberación de Sudán — entre ellas el grupo con el apoyo mayoritario de los 
1706 (2006), del 31 de agosto de 2006, decidió que la UNMIS se despliegue en Darfur y, en consecuencia, solicitó el consentimiento del gobierno de Unidad Nacional para ese despliegue. ${ }^{65}$ Decidió además, que la UNMIS se refuerce con un máximo de 17,300 efectivos militares y con un componente civil adecuado que incluya un máximo de 3,300 efectivos de policía civil y un máximo de 16 unidades constituidas de policía. No obstante, Sudán se negó a cumplir esta resolución.

Asimismo, el Consejo de Seguridad, en sus resoluciones S/RES/ 1714 (2006) y S/RES/1755 (2007), exhortó a las partes a que respeten sus compromisos y apliquen cabalmente y sin demora todos los aspectos de los acuerdos, y exhortó a las partes que no hayan firmado el Acuerdo de Paz de Darfur a que lo hagan cuanto antes y se abstengan de todo acto que entorpezca la aplicación del Acuerdo.

Finalmente, luego de conversaciones con el gobierno sudanés, el Consejo de Seguridad, mediante la resolución 1769 (2007), del 31 de julio de 2007, decidió establecer una operación híbrida de la Unión Africana y las Naciones Unidas en Darfur (UNAMID), integrada por casi 26,000 efectivos. Esta fuerza de paz, que se desplegaría en 2008, actuará conforme al capítulo VII de la Carta de la ONU, es decir, usará la fuerza para proteger a su personal, a los civiles y apoyar el Acuerdo de Paz de Darfur. Lamentablemente, el Movimiento Justicia e Igualdad (JEM) rechaza el despliegue de fuerzas de la ONU y mantiene una lucha abierta contra el gobierno sudanés.

A la fecha, de los 26,000 efectivos que establece la resolución, sólo se han desplegado 9,000, lo que hace suponer la falta de voluntad de la comunidad internacional para solucionar el problema rápidamente. Empero, el 31 de julio de 2008, el Consejo de Seguridad prorrogó la UNAMID por un año más. ${ }^{66}$

fur, el grupo étnico más grande de Darfur - y el Movimiento Justicia e Igualdad (JEM, por sus siglas en inglés) se negaron a firmarlo.

65 El secretario general de la ONU, en su informe S/2006/591, del 28 de julio de 2006, dirigido al Consejo de Seguridad, ya había recomendado el establecimiento de una fuerza de mantenimiento de la paz de la ONU en Darfur, con el mandato de proteger a la población civil, y el refuerzo de la ONU para aumentar la capacidad de la AMIS durante el periodo de transición hasta el despliegue de la fuerza de mantenimiento de la paz de la ONU.

66 S/RES/1828 (2008), aprobada por el Consejo de Seguridad en su 5947a. sesión, celebrada el 31 de julio de 2008 . 


\section{2. ¿Parálisis del Consejo de Seguridad?}

El Consejo de Seguridad de la ONU está conformado por 15 miembros, 5 de los cuales son permanentes y tienen derecho a veto. ${ }^{67}$ Esta situación ha imposibilitado muchas veces la acción del Consejo, ya que los intereses de las grandes potencias no siempre son coincidentes. Ya en la última guerra civil sudanesa, norte (árabe musulmán) vs. sur (cristiano animista), se evidenció el apoyo francés al norte y el de Estados Unidos e Italia hacia el sur.

Asimismo, hay que recordar que los actores involucrados en este conflicto no son sólo el gobierno sudanés y las guerrillas sudanesas, sino que Sudán cuenta con el apoyo de Francia, China, la Liga Árabe y países árabe-musulmanes; en cambio a "Darfur" apoyarían los Estados Unidos y sus aliados; finalmente, las organizaciones internacionales implicadas: la UE, la UA (Unión Africana) y la ONU, también forman parte del conflicto. ${ }^{68}$

Francia y China ${ }^{69}$ tienen inversiones petroleras importantes en Sudán, por ello, algunos analistas afirman que la guerra civil en Sudán es "otra guerra del petróleo". ${ }^{70}$

La Liga Árabe apoya políticamente a Sudán, pero también tiene intereses económicos que se derivan de los tratados de libre comercio. Estados Unidos tienen intereses políticos que engloban la lucha contra Al Qaeda y la democratización árabe e intereses económicos por el petróleo y otros recursos naturales. ${ }^{71}$

Finalmente, tanto Rusia como China constantemente suministran armas al gobierno dictatorial de Omar Hasan Ahmad al-Bashir, constituyéndose así en el sostén del régimen de Jartum. ${ }^{72}$

67 La República Popular China, la República francesa, la Federación de Rusia, el Reino Unido de Gran Bretaña e Irlanda del Norte y los Estados Unidos de América.

68 Un trabajo más amplio sobre los intereses de los actores involucrados en el conflicto Ruiz Miguel, Carlos, "Implicaciones geopolíticas del conflicto del Darfur", Real Instituto Elcano de Estudios Internacionales y Estratégicos, ARI, núm. 141, 20 de septiembre de 2004, http://www.realinstitutoelcano.org/analisis/575/575.pdf.

69 China, principal socio comercial de Sudán, es a la vez su mayor comprador de petróleo.

70 Véase Nso, Sara, op. cit., nota 56, p. 2.

71 Ibidem, pp. 3-5.

72 Capital de Sudán y centro de poder de la dictadura islámica sudanesa. 
A pesar de estas atingencias, hay que reconocer que en marzo de 2005, el Consejo de Seguridad remitió el conflicto a la Corte Penal Internacional (CPI) y al menos ha desplegado una operación de paz en Darfur, sin embargo, la situación todavía es crítica.

Finalmente, es pertinente afirmar que teniendo en cuenta que el fiscal de la CPI informa cada 6 meses al Consejo de Seguridad sobre el progreso de sus investigaciones en Darfur, y que el 14 de julio de 2008, presentó a los jueces una acusación ${ }^{73}$ contra el actual presidente de Sudán, Omar al-Bachir, por genocidio, crímenes de guerra y lesa humanidad, las Naciones Unidas no están asumiendo su responsabilidad de proteger.

\section{CONCLUSIONES}

1. El conflicto de Darfur se ha convertido en un reto humanitario de dimensiones dantescas.

2. Las Naciones Unidas no han sabido actuar ante la amenaza contra la seguridad humana que constituye la grave crisis humanitaria en Darfur.

3. La crisis humanitaria que sufre Darfur es un indicador objetivo que permite afirmar que existe la necesidad de una intervención militar de las Naciones Unidas para salvaguardar las vidas de sus pobladores.

4. Las violaciones masivas y sistemáticas a los derechos humanos que devengan en graves crisis humanitarias constituyen los fundamentos jurídicos para una intervención militar en Darfur.

5. Los fundamentos jurídicos para la intervención militar en Darfur se basan en la doctrina de la responsabilidad de proteger.

6. La Carta de las Naciones Unidas contempla los mecanismos jurídicos vigentes para poder realizar una intervención militar en Darfur; sin embargo, el Consejo de Seguridad ha demostrado una vez más su ineficacia ante este tipo de amenazas a la paz y la seguridad internacionales.

7. En vista que Darfur constituye una pieza importante en el equilibrio geoestratégico tanto africano (mundo árabe y mundo negro) como universal (Occidente-musulmán y Occidente-China), vemos lejana una solución integral a la crisis humanitaria.

73 La consecuencia inmediata fue el retiro de "personal" no esencial de Naciones Unidas de la zona. 


\section{BIBLIOGRAFÍA}

\section{Documentos internacionales}

Carta de las Naciones Unidas de 1945.

Convenio sobre la Prevención y Castigo del Delito de Genocidio de 1948.

A/54/2000, "We the Peoples: the Role of the United Nations in the Twenty-First Century", 27 de marzo de 2000.

A/RES/60/1, Documento Final de la Cumbre Mundial 2005, 24 de octubre de 2005.

S/2004/453, Informe del Secretario General sobre el Sudán, del 3 de junio de 2004.

S/RES/1547 (2004), aprobada por el Consejo de Seguridad en su 4988a. sesión, celebrada el 11 de junio de 2004, párrafo 6.

S/RES/1556 (2004), aprobada por el Consejo de Seguridad en su 5015a. sesión, celebrada el 30 de julio de 2004.

S/RES/1564 (2004), aprobada por el Consejo de Seguridad en su 5040a. sesión, celebrada el 18 de septiembre de 2004, párrafo 12.

S/RES/1590 (2005), aprobada por el Consejo de Seguridad en su 5151a. sesión, celebrada el 24 de marzo de 2005.

S/RES/1593 (2005), aprobada por el Consejo de Seguridad en su 5158a. sesión, celebrada el 31 de marzo de 2005.

S/RES/1672 (2006), aprobada por el Consejo de Seguridad en su 5423a. sesión, celebrada el 25 de abril de 2006.

S/RES/1714 (2006), aprobada por el Consejo de Seguridad en su 5545a. sesión, celebrada el 6 de octubre de 2006.

S/RES/1755 (2007), aprobada por el Consejo de Seguridad en su 5670a. sesión, celebrada el 30 de abril de 2007.

S/RES/1828 (2008), aprobada por el Consejo de Seguridad en su 5947a. sesión, celebrada el 31 de julio de 2008.

S/PRST/2003/16, declaración del presidente del Consejo de Seguridad, del 10 de octubre de 2003.

\section{Jurisprudencia}

Corte Internacional de Justicia, Caso sobre las Actividades militares y paramilitares en y en contra de Nicaragua, sentencia del 27 de junio de 1986. 


\section{Documentos en línea}

Amnistía Internacional, AFR 20/006/2006, Chad/Sudán, El fruto de las semillas de Darfur. Ataques étnicos en Chad de las milicias yanyawid de Sudán, 28 de junio de 2006, http://web.amnesty.org/library/ index/eslafr200062006.

BBC Mundo, Darfur: claves de una tragedia, 26 de mayo de 2005, http: //news.bbc.co.uk/hi/spanish/international/newsid_4225000/42258 23.stm.

CIISE (Comisión Internacional sobre Intervención y Soberanía de los Estados), "La responsabilidad de proteger", diciembre de 2001, http: //www.iciss.ca/pdf/Spanish-report.pdf.

Dirección General de Comunicación Exterior de España, "Sudán", Ministerio de Asuntos Exteriores y de Cooperación de España, junio de 2004, http://www.mae.es/NR/rdonlyres/03CC364B-AA94-41458303-90CB 98BA3A9A/4347/Sudan1.pdf.

Human Right Watch, "Darfur: Humanitarian Aid under Siege", núm. 1, mayo de 2006, http://hrw.org/backgrounder/africa/sudan0506/dar fur0506.pdf.

NsO, Sara, "La crisis de Darfur y el futuro de la seguridad africana", UNISCI Discussion Papers, octubre de 2004, http://www.ucm.es/BU CM/revistas/cps/16962206/articulos/UNIS0404330020A.PDF.

PNUD (Programa de la ONU para el Desarrollo), Informe sobre Desarrollo Humano 2005, Nueva York, Ediciones Mundi-Prensa, 2005, http://hdr.undp.org/reports/global/2005/espanol/pdf/HD R05_sp_ complete.pdf.

Ruiz Miguel, Carlos, "Implicaciones geopolíticas del conflicto del Darfur", Real Instituto Elcano de Estudios Internacionales y Estratégicos, ARI, núm. 141, 20 de septiembre de 2004, http://www.realins titutoelcano.org/analisis/575/575.pdf.

\section{Libros}

BARBERIS, Julio et al., Sujetos del derecho internacional, Buenos Aires, Ábaco de Rodolfo Depalma, 1998.

CARrillo SAlcedo, Juan Antonio, Curso de derecho internacional público, Madrid, Tecnos, 1994.

DIEZ DE VELASCO, Manuel, Instituciones de derecho internacional público, Madrid, Tecnos, 2001. 
HolzGRefe, J. L. "The Humanitarian Intervention Debate", en HolzGREFE, J. L. y KeOHANE, Robert O. (eds.) Humanitarian Intervention: Ethical, Legal And Political Dilemmas, Cambridge, Cambridge University Press, 2003, pp. 15-52.

Remiro Brotóns, Antonio et al., Derecho internacional, Madrid, McGraw-Hill, 1997.

SAndoz, Yves et al., Comentario del Protocolo del 8 de junio de 1977 adicional a los Convenios de Ginebra del 12 de agosto de 1949 relativo a la protección de las víctimas de los conflictos armados internacionales (Protocolo I), t. II, Bogotá, CICR, Plaza \& Janés, 2000.

SHAw, Malcom N., International Law, Cambridge, Cambridge University Press, 1997.

\section{Artículos}

AKehurst, Michael B., "Civil War", en Bernhardt, R. (ed.), Encyclopedia of Public International Law, vol. I, 1992, pp. 597-603.

ModeEn, Tore, "Aaland Islands", en BERNHARDT, R. (ed.), Encyclopedia of Public International Law, vol. I, 1992, pp. 1-3.

Revilla Montoya, Pablo César, "Chechenia: ¿separatismo, terrorismo o libre determinación de los pueblos?", Revista de Investigación Jurídica Docentia et Investigatio, Lima, vol. 7, núm. 1, noviembre de 2005, pp. 187-197.

—_ "Hacia la responsabilidad de proteger. Bases jurídicas para una respuesta colectiva ante crisis humanitarias", Anuario Mexicano de Derecho Internacional, vol. III, 2007, pp. 643-673.

THÜRER, Daniel, "Self-determination", en BERNHARDT, R. (ed.), Encyclopedia of Public International Law, vol. IV, 2000, pp. 364-374. 